\title{
Alfa autista: uma aplicação mobile para o auxílio na alfabetização do autista através de método fônico. Um estudo de caso na APAE-Marabá
}

\author{
José Carlos Pantoja da Silva ${ }^{1}$, Aline Farias Gomes de Sousa ${ }^{2}$, Raimundo Martins \\ de Araújo Júnior ${ }^{3}$ \\ ${ }^{1}$ Centro de Informática - Universidade Federal de Pernambuco (UFPE) \\ CEP - 50.740-560 - Recife - PE - Brasil \\ ${ }^{2}$ Faculdade de Computação e Engenharia Elétrica - Universidade Federal do Sul e \\ Sudeste do Pará (UNIFESSPA) \\ CEP - 68.505-080 - Marabá - PA - Brasil \\ ${ }^{3}$ Universidade Federal do Oeste do Pará (UFOPA) \\ CEP - 68.270-000 - Oriximiná - PA - Brasil \\ jcps@cin.ufpe.br, alinefarias@unifesspa.edu.br, \\ raimundo.araujo@ufopa.edu.br
}

\begin{abstract}
This paper aims to present the process of developing a mobile application with the purpose of offering a teaching / learning method for students suffering from Autism Spectrum Disorder (ASD). In the course of this research will be approached concepts of autism, difficulties of autistic people in relation to learning and how this software can help in the process of literacy of these students through the phonic method, aiming at an improvement in communication in the autistic in the social and school environment.
\end{abstract}

Resumo. Esse artigo tem por objetivo apresentar o processo do desenvolvimento de um aplicativo para dispositivos móveis com o intuito de oferecer um método de ensino/aprendizagem para alunos que sofrem de Transtorno do Espectro Autista (TEA). No decorrer desta pesquisa será abordado conceitos de autismo, dificuldades das pessoas autistas em relação a aprendizagem e como este software pode ajudar no processo de alfabetização destes alunos através do método fônico, objetivando uma melhora na comunicação no autista no ambiente social e escolar.

\section{Introdução}

Em sua pesquisa, Santos et al (2012) diz que, o autismo é considerado, atualmente, um transtorno do desenvolvimento de causas neurobiológicas, definido de acordo com critérios eminentemente clínicos, que afeta as áreas de interação social, comunicação e comportamento de um indivíduo. Os sintomas evidenciam-se antes dos 03 anos de idade e podem ser percebidos em crianças que apresentam atraso na fala, ausência de contato 
VII Congresso Brasileiro de Informática na Educação (CBIE 2018)

Anais do XXIX Simpósio Brasileiro de Informática na Educação (SBIE 2018)

visual, movimentos estereotipados, isolamento social e apego excessivo a rotinas, dentre outras características.

(TAYLOR, 1980) frizou que os software educacionais são classificados em tutor (o software tem a capacidade de instruir o aluno), tutorado (o software permite ao aluno instruir o meio tecnológico de aprendizagem) e ferramenta (o software com o qual o aluno manipula à informação).

Desta forma, tendo em vista a problemática do TEA e a crescente inclusão de pessoas com essa patologia nas escolas, este trabalho visa auxiliar os professores de alunos com TEA no seu processo de alfabetização através do método da fonética.

Neste contexto se observa que também há uma necessidade de software que sirvam como uma ferramenta complementar de apoio para os professores atuantes no processo de inclusão de estudantes com TEA. A APAE de Marabá conta com três profissionais que trabalham diretamente com as pessoas com essa patologia, porém pela falta de um software que auxilie a alfabetização dos alunos através do método fônico, este é descartado, apesar dele ser de grande valia para que as pessoas autistas consigam ter um aprendizado eficaz da leitura e da escrita.

\section{Trabalhos correlatos}

Existem alguns trabalhos no Brasil para o auxílio da aprendizagem de crianças autistas. (CARVALHO E LIMA, 2014) desenvolveram o aplicativo Perceber que é um software educacional de atividades para o desenvolvimento da percepção visual de estudantes autistas clássicos, foi desenvolvido no ano de 2014, seus autores foram Andrea de Carvalho e Felipe Viterbo. Este software foi desenvolvido para ser executado em plataforma Android, que é um sistema operacional construído sobre o núcleo Linux. O software traz em sua interface gráfica tons de cores suaves, conforme descrição dos autores (figura 1), atendendo as recomendações que visam evitar e dispersar a atenção ou confundir o estudante 
VII Congresso Brasileiro de Informática na Educação (CBIE 2018)

Anais do XXIX Simpósio Brasileiro de Informática na Educação (SBIE 2018)

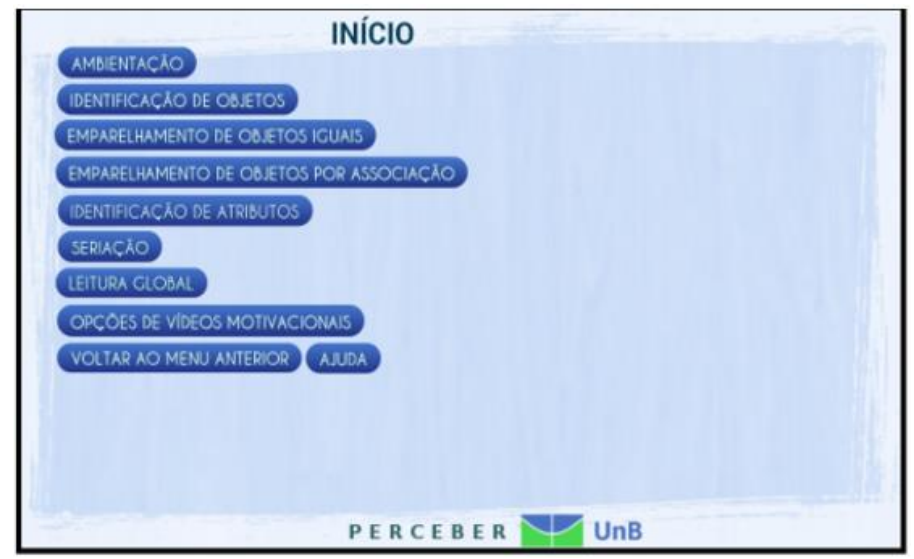

Figura 1. Menu software perceber.

Essa aplicação traz uma série de atividades voltadas para o aprendizado e desenvolvimento do público alvo. Nas atividades de ambientação, o estudante pode ser observado e avaliado em sua coordenação motoras, visto que nesse módulo permite ao estudante tocar e arrastar objetos até um determinado lugar proposto pela aplicação. O exercício de identificação de objetos, solicita ao aluno tocar em um objeto específico solicitado pelo aplicativo.

(MARTINS et al, 2016) O software Litera Azul (figura 2) foi desenvolvido no ano de 2016 pelos autores Gabriel Martins, Jamilli dos Santos, Elza Uchoa, Arrelias e Ederson Leite, tem como objetivo dar apoio a alfabetização de crianças com autismo, aplicando o método TEACCH, que se baseia na organização do ambiente físico através de rotinas estruturadas e sistemas de trabalho de forma a adaptar o ambiente para tornar o mesmo mais fácil para a criança compreende-lo assim como também o que se espera dela.

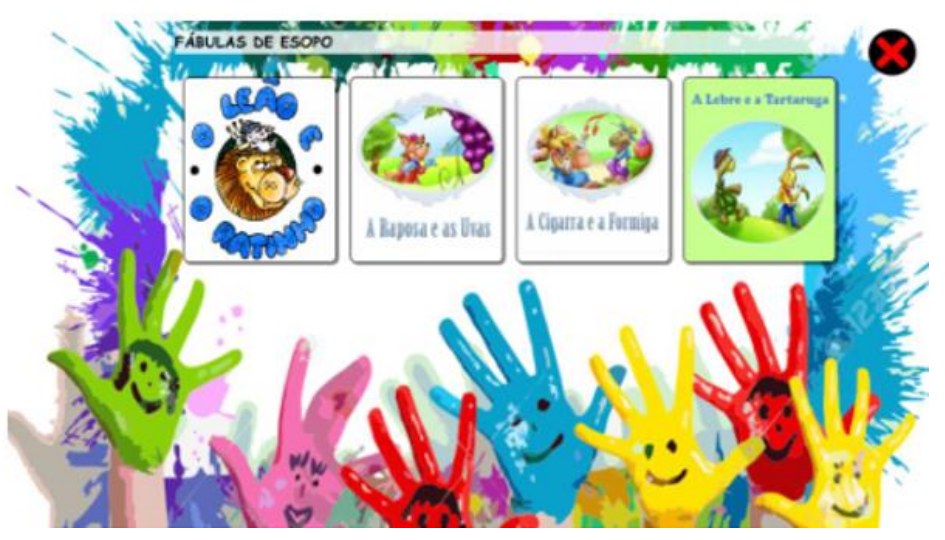

Figura 2. Aplicativo Litera azul. 
VII Congresso Brasileiro de Informática na Educação (CBIE 2018)

Anais do XXIX Simpósio Brasileiro de Informática na Educação (SBIE 2018)

\section{Aplicativo}

Segundo a pesquisa de Serra (2017) Estudos comprovam que crianças que compreendem o sentido fonético da língua, tornam-se bons leitores. $\mathrm{O}$ alfa autista é um aplicativo de aprendizagem que tem o intuito de auxiliar os profissionais da APAE do município de Marabá, no processo de alfabetização dos alunos com TEA através da fonética.

O Alfa autista foi desenvolvido para dispositivos Android, sendo testado na APAE do município de Marabá que, em parceria com o centro educacional especializado "Casa Despertar", visam proporcionar condições que favorecem a inclusão na sociedade dos educandos com deficiência intelectual e afins, desenvolvendo programas e atendimentos educacionais com profissionais especializados. A fase de prototipação do aplicativo teve constantes visitas e entrevistas com os profissionais pedagógicos do local, os quais expuseram opiniões e ideias para a construção do aplicativo, baseados nas necessidades educacionais do ambiente, respeitando os limites do público-alvo.
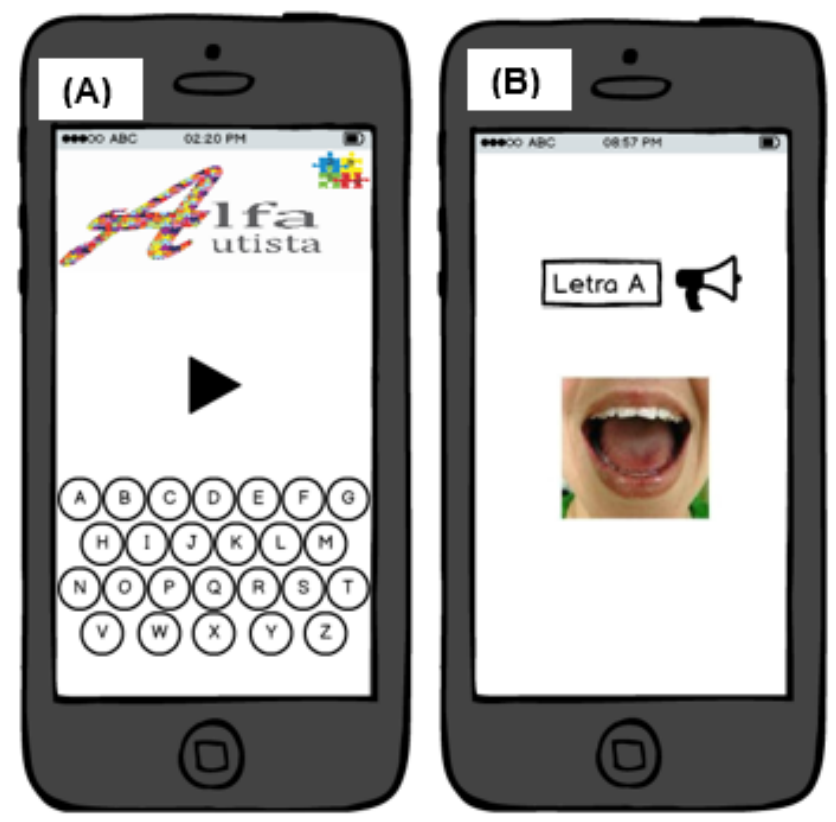

Figura 3. (a) Tela de aprendizagem; (b) Tela do fonema. 
VII Congresso Brasileiro de Informática na Educação (CBIE 2018)

Anais do XXIX Simpósio Brasileiro de Informática na Educação (SBIE 2018)

O aplicativo Alfa autista conta com um layout em cores que representam a simbologia da síndrome do Autismo. Na figura acima pode ser visto a tela funcional do aplicativo, sendo a Figura 3 (a) a tela de aprendizagem e a Figura 3 (b) a tela do fonema.

\section{Considerações finais}

O objetivo inicial do trabalho foi alcançado através do desenvolvimento do aplicativo Alfa Autista. Para as versões posteriores já trabalhamos na ideia de utilizar plataformas com mais abrangência, exemplo da linguagem HTML5, que possui vários recursos que serão de inteira utilidade para a melhoria das funções do aplicativo, fazendo com que o mesmo possa ser utilizado em qualquer tipo de dispositivo, seja Android, IOs, etc.

Foi realizada uma avaliação sucinta com os professores e alunos da APAE relativo ao aplicativo proposto e desenvolvido. Porém, devido a quantidade minima de páginas de um artigo resumido e, por necessitar de uma avaliação mais elaborada do que a inicial, a mesma não foi disponibilizada nesse trabalho.

Segundo avaliação preliminar, dos professores, através de um questionário de avaliação do aplicativo Alfa Autista, aplicado ao final da fase de validação, o aplicativo foi considerado como uma ferramenta adequada e motivadora, atendendo de forma satisfatória o seu público alvo. Além de ser uma ferramenta que trouxe entusiasmo aos professores, os quais sentem falta de aplicativos que os ajudem no ensino-aprendizagem das crianças com TEA, destacando que no âmbito escolar há uma carência de recursos pedagógicos para os profissionais que trabalham diretamente com esse público.

\section{Referências}

Android. Disponível em: https://developer.android.com/docs/. [Acesso em: 20 ago. 2018].

CARVALHO, A.; LIMA, F. V.; PERCEBER: SOFTWARE EDUCACIONAL DE ATIVIDADES PARA O DESENVOLVIMENTO DA PERCEPÇÃO VISUAL DE ESTUDANTES AUTISTAS CLÁSSICOS. BRASÍLIA, 2014.

Martins, G S; Dos Santos, J D, Moura, E U; Arrelias J.S; Leite, E W F. LITERATURA AZUL: PROTÓTIPO DE SOFTWARE DE APOIO À ALFABETIZAÇÃO DE AUTISTAS. ANAIS DOS WORKSHOPS DO V CBIE. UBERLÂNDIA: 2016, p. 205.

Santos, Maria Vanessa Pereira dos, et al. "Proposta de Jogo usando Tecnologias Assistivas para Auxílio na Rotina Diária de Crianças Autistas." VII CONNEPICongresso Norte Nordeste de Pesquisa e Inovação. 2012.

SERRA, D.; Alfabetização de Alunos com TEA - Da teoria à prática. Conautismo. Disponível em <https://neurosaber.com.br/alfabetizacao-com-tea/>. Acesso em: 19 de março de 2017.

TAYLOR, R.P. ed. (1980) The Computer in the School: Tutor, Tool, Tutee. Teachers College Press, New York.

Victal, Enza R. N. Menezes C. de S. Avaliação para Aprendizagem baseada em Jogos: Proposta de um Framework. SBGAMES 2015, http://www.sbgames.org/sbgames2015/anaispdf/cultura-full/147549.pdf [Acesso em: 10 de agosto. 2018]. 